\title{
Beak Dipping Route of Administration
}

National Cancer Institute

\section{Source}

National Cancer Institute. Beak Dipping Route of Administration. NCI Thesaurus. Code C149353.

Administration of a veterinary medicinal product by dipping the beak of birds into an aqueous solution of the medicinal product. 